\title{
Experimental and numerical study of insulation walls containing a composite layer of PU-PCM and dedicated to refrigerated vehicle
}

\author{
Benoit Michel $^{\mathrm{a}}$, Patrick Glouannec ${ }^{\mathrm{a}, *}$, Adrien Fuentes $^{\mathrm{a}}$, Philippe Chauvelon ${ }^{\mathrm{a}}$ \\ a Institut de Recherche Dupuy de Lôme (IRDL), Université de Bretagne Sud, Centre de recherche, BP 92116, \\ 56321 Lorient Cedex, France. \\ * Corresponding author: \\ E-mail: patrick.glouannec@univ-ubs.fr
}

\section{Highlights}

A design study of an insulation wall for a refrigerated vehicle is carried out.

PU-PCM composite plates with high energy storage density are characterized.

Experimental and numerical studies of multilayer insulation walls are performed.

\section{Keywords}

Multilayers insulation design, refrigerated vehicle, PU-PCM composite, phase change material

\begin{abstract}
This paper presents an experimental and numerical design approach for a multi-layer insulation wall dedicated to refrigerated vehicles and containing a composite layer of PU-PCM foam. The thermal performances of the insulation walls and the thermal properties of the insulation materials are investigated using complementary experimental tools at different scales (a few $\mathrm{mg}$ to $\approx 100 \mathrm{~g}$ ). In addition, a 1D FEM model of heat and mass transfer within the wall is implemented.

Two PU-PCM composites with high energy storage capacities (i.e. high PCM mass rate) are characterized at small and large scales. Although local inhomogeneity of the distribution of PCM microbeads within the composite material is highlighted, the complementary experiments allowed measuring the average PCM mass rates of the composite materials: $35 \% \mathrm{w}$ and $43 \% \mathrm{w}$. Furthermore, the study of the multilayer insulation wall shows the importance of the location of the composite layer inside it. Four multilayer wall geometries were tested to define the optimization trails. The energy crossing the inner face of the insulation wall during the "road delivery period" fell by as much as $18 \%$ for the scenario, materials and geometries studied. It was observed that the composite material must be placed close to the external wall of the vehicle.
\end{abstract}

\section{Nomenclature}

c specific heat capacity, $\mathrm{J} \cdot \mathrm{kg}^{-1} \cdot \mathrm{K}^{-1}$

e thickness, $\mathrm{m}$

$E \quad$ energy density, $\mathrm{Wh} \cdot \mathrm{m}^{-2}$

$h \quad$ specific enthalpy

$K \quad$ heat transfer coefficient, $\mathrm{W} \cdot \mathrm{m}^{-2} \cdot \mathrm{K}^{-1}$

$L \quad$ latent heat, $\mathrm{J} \cdot \mathrm{g}^{-1}$

Q specific heat, $\mathrm{J} \cdot \mathrm{g}^{-1}$

$T$ temperature, $K$

$x \quad$ PCM weight content, $\mathrm{kg}_{\mathrm{PCM}} / \mathrm{kg}_{\text {composite }}$ or \%

Greek symbols

$\begin{array}{ll}\phi & \text { heat flux density, } \mathrm{W} \cdot \mathrm{m}^{-2} \\ \text { Indices } & \\ \text { composite } & \text { PU-PCM composite } \\ \text { eq } & \text { equivalent } \\ f & \text { freezing } \\ m & \text { melting } \\ P C M & \text { phase change material } \\ P U & \text { polyurethane } \\ w & \text { wall } \\ 1 & \text { vehicle exterior wall }\end{array}$

1 vehicle exterior wall 


\section{Introduction}

Refrigerated transport is a key link in the cold chain. It is necessary for maintaining the quality and prolonging the shelf-life of fresh, frozen and perishable products during transportation. Currently, about 4 million refrigerated road vehicles are in use in the world and food refrigeration accounts for roughly $40 \%$ of the total energy requirement during distribution. It is forecast that global road freight transport will have grown by $2.5 \%$ a year by $2030[1,2]$.

The increasing use of refrigerated transport is driving this industrial sector to seek ways of reducing energy consumption, especially by improving insulation design.

The legislation concerning all types of refrigerated vehicles used for the transport of perishable food products requires the application of the ATP agreements (Agreement on the International Carriage of Perishable Foodstuffs) drafted by the United Nations in 1970 [3]. This agreement provides specifications for insulated bodies and equipment. According to these standards, transportation equipment (insulation and body walls) has either normal insulation (for which the overall heat transfer coefficient $K$ is equal to or less than $0.7 \mathrm{~W} \cdot \mathrm{m}^{-2} \cdot \mathrm{K}^{-1}$ ) or reinforced insulation (for which the $K$ coefficient is equal to or less than $\left.0.4 \mathrm{~W} \cdot \mathrm{m}^{-2} \cdot \mathrm{K}^{-1}\right)$. These insulation levels are not very ambitious and involve the use of high power chillers.

Today, the insulating structure of refrigerated vehicles is commonly composed of a thick layer of expanded polyurethane (PU) foam [4]. This has the advantages of having low thermal conductivity (around $0.023-0.026 \mathrm{~W} \cdot \mathrm{m}^{-1} \cdot \mathrm{K}^{-1}[5]$ ), good mechanical strength, low hydrophilicity and low cost. This material can also be recycled by grinding or by chemical treatment, but its manufacture requires a great deal of energy. Nevertheless, changes made to the expander agents of PU foam over the past ten years have led to a slight decrease in its insulating capacity [6]. Furthermore, PU foam has low thermal inertia and does not allow decreasing peaks in cooling demand due to changes in external thermal conditions. For example, solar irradiation can cause the cooling peak to increase by as much as $180 \%[7,8]$.

In recent years, many new insulation materials have been studied and placed on the market (aerogel, phase change materials (PCM), etc.). Among them, phase change materials seem promising candidates. These materials have high latent heat values and are capable of storing or releasing a large amount of energy during phase changes within minor temperature variations. These materials have been widely studied for building [9] and for cold storage applications $[10,11]$. The use of PCMs in transport refrigeration systems has attracted far less attention than in buildings. However, in a recent study Oró et al. [12] showed that in Europe, the use of PCM in refrigerated vehicles could reduce energy consumption from 959 to $12.788 \mathrm{GWh} / \mathrm{yr}$.

Few studies have dealt with the integration of PCM layers in the insulation walls of refrigerated vehicles (so-called macro-encapsulation of PCM, i.e. encapsulation in a container larger than $1 \mathrm{~cm}$ in diameter [13]), and promising results have been obtained [7,8,14]. In particular, experimental results have shown a reduction of both the heat transfer peak across the wall and daily cold demand, compared to a standard insulation wall. Thus Ahmed et al. [8] carried out an experimental study of PCM inclusion in a standard refrigerated trailer wall of $1.22 \mathrm{~m}^{3}$. Copper pipes 
were filled with paraffin-based PCM and integrated in a PU insulation wall. The experiment resulted in an average reduction of peak heat transfer of $29.1 \%$ and an average energy saving of $16.3 \%$, compared to a standard refrigerated trailer. Moreover, Glouannec et al. [7] introduced a layer of commercial PCM (Energain ${ }^{\circledR}$ ) in a multilayer insulation wall of $1 \mathrm{~m}^{2}$ dedicated to refrigerated vehicles. For a standard scenario, experiments have shown a decrease in energy consumption by about $25 \%$ compared to a reference case. Finally, in a recent work, Copertaro et al. [14] performed a numerical study of the integration of a PCM layer in a refrigerated container envelope. For a typical summer day under the Italian climate, the authors observed a decrease of the heat load peak of around $20 \%$ and a reduction of the daily energy demand of around $4.5 \%$ compared to a standard wall, without a PCM layer.

The combination of PU foams and micro-encapsulated phase change materials - i.e. PU-PCM foam - is an interesting way to combine the advantage of thermal insulation and thermal energy storage capacity. In such composite foams, PCM micro-capsules are dispersed in a polyurethane foam matrix during the production process, i.e. directly during the mixing stage of the liquid reaction components. In recent years, several papers have investigated the incorporation of PCM in a PU matrix [15-18]. Most of these studies focused on synthesis methods and the thermal energy storage capacity of the composite but few studies have dealt with thermal evaluation of PU-PCM foams in use. Moreover, all these studies focused on composites with a low PCM mass content $(<25 \%)$ [18]. Promising results have been obtained, especially for refrigerated transport applications. Thus the feasibility of the incorporation process has been demonstrated though no significant evolution of thermal conductivity has been observed for a PCM mass content from $4.5 \%$ to $13.2 \%$ [13].

To increase the specific latent heat of the PU-PCM composite and therefore its energy storage density, it is necessary to increase its PCM mass rate. This paper focuses on the insulation walls of a refrigerated vehicle containing a composite layer of PU-PCM foam with high energy storage capacity (i.e. PCM rate higher than $40 \%_{\mathrm{w}}$ ). The objective is to present the design approach of such insulation walls, taking into account the thermal properties of both the composite layer and the multilayer insulating wall, using experimental and numerical methods at different scales (from a few $\mathrm{mg}$ to a wall measuring $12.5 \times 12.5 \mathrm{~cm}^{2}$ ).

The first part of this paper is dedicated to the characterization of the composite PU-PCM wall, notably the measurement of its thermal properties (equivalent specific heat, thermal conductivity) at small (a few $\mathrm{mg}$ ) and large scale $\left(12.5 \times 12.5 \mathrm{~cm}^{2}\right)$ and the study of its thermal behavior using a typical refrigerated vehicle scenario. Secondly, the thermal response of a multilayer wall containing a PU-PCM layer and dedicated to refrigerated vehicles is analyzed using experimental and numerical approaches to define the optimal location and thickness of the composite layer. Thus an experiment at wall scale and a 1D dynamic model of heat and mass transfer within the insulation wall are implemented and described.

\section{Material and methods}

\subsection{Composite elaboration and characterization}

\subsubsection{The materials studied}

PU-PCM composite plates were manufactured by the material vendor, with two different proportions (40\% and $50 \%$ ) of a commercial microencapsulated phase change material (C18 Inertek 29 [19]) produced by in situ polymerization of PCM in microcapsules composed of aminoplast. 
The microencapsulated PCM was mixed by mechanical stirring in a mixture of polyol and isocyanate and then poured into an open mold to produce $2 \mathrm{~cm}$-thick square slabs with $25 \mathrm{~cm}$ sides. Each composite slab was then cut into four square samples $12.5 \mathrm{~cm} \times 12.5 \mathrm{~cm}$ to measure the thermal properties of these composite materials and test various configurations of multi-layer insulating walls.

\subsubsection{Thermophysical properties}

a) Density

The four samples of each PU-PCM composite were characterized. Their densities, measured at $20^{\circ} \mathrm{C}$, are provided in the Logically, the average density of PU-PCM plates increases with the proportion of PCM. It increased from $160 \mathrm{~kg} / \mathrm{m}^{3}$ for composite 1 (containing $40 \%{ }_{\mathrm{w}} \mathrm{PCM}$ ) to $217 \mathrm{~kg} / \mathrm{m}^{3}$ for composite 2 (containing $50 \%_{\mathrm{w}} \mathrm{PCM}$ ).

Moreover, for each composite, there was a slight discrepancy in the measures between the four samples tested. Thus a standard deviation of 15 and $14 \mathrm{~kg} / \mathrm{m}^{3}$ was observed between the different samples of composites 1 and 2, respectively. These differences in density showed a slight inhomogeneity at the macroscopic scale of the PU-PCM foam formation.

In the following parts of this paper, only the first plate of each composite is studied.

Table 1.

Logically, the average density of PU-PCM plates increases with the proportion of PCM. It increased from $160 \mathrm{~kg} / \mathrm{m}^{3}$ for composite 1 (containing $40 \%_{w} P C M$ ) to $217 \mathrm{~kg} / \mathrm{m}^{3}$ for composite 2 (containing $\left.50 \%{ }_{\mathrm{w}} \mathrm{PCM}\right)$.

Moreover, for each composite, there was a slight discrepancy in the measures between the four samples tested. Thus a standard deviation of 15 and $14 \mathrm{~kg} / \mathrm{m}^{3}$ was observed between the different samples of composites 1 and 2, respectively. These differences in density showed a slight inhomogeneity at the macroscopic scale of the PU-PCM foam formation.

In the following parts of this paper, only the first plate of each composite is studied.

Table 1: Density of the four samples of the composites PU-PCM 1 and 2.

\begin{tabular}{|l|c|c|}
\hline Plate & $\begin{array}{c}\text { Composite } \mathbf{1}\left(\mathbf{4 0} \%_{\mathbf{w}} \mathbf{P C M} \mathbf{~}^{*}\right) \\
\mathbf{\rho}\left(\mathbf{k g} / \mathbf{m}^{\mathbf{3}}\right)\end{array}$ & $\begin{array}{c}\text { Composite } \mathbf{2}\left(\mathbf{5 0} \%_{\mathbf{w}} \mathbf{P C M} \mathbf{*}^{*}\right) \\
\mathbf{\rho}\left(\mathbf{k g} / \mathbf{m}^{\mathbf{3}}\right)\end{array}$ \\
\hline $\mathbf{1}$ & 163 & 223 \\
\hline $\mathbf{2}$ & 152 & 231 \\
\hline $\mathbf{3}$ & 180 & 218 \\
\hline $\mathbf{4}$ & 146 & 198 \\
\hline Average & 160 & 217 \\
\hline
\end{tabular}

*Given by the material seller.

\section{b) Equivalent specific heat capacity}

The enthalpy of the pure PCM and the PU-PCM composites 1 and 2 was measured using a differential scanning calorimeter (MDSC3-SETARAM). The cell volume of this device was $1 \mathrm{ml}$. The mass of the samples characterized varied from 50 to $100 \mathrm{mg}$. Thermal analysis was conducted over a temperature range of $\left[0 ; 22^{\circ} \mathrm{C}\right]$. Furthermore, due to the high energies involved during phase change transformations and the different heat transfer phenomena omitted during the DSC measurements, namely the non-uniformity of the sample temperature (thermal conduction), the time required to heat or cool the sample (inertia), and convective transfers within the microencapsulated PCM beads 
[20], using the heat flow measured by the calorimeter directly can lead to errors in determining the enthalpy of the PCM. Thus, in the case of excessive sample heating and cooling rates, direct use of the heat flux measured by DSC causes the solidification curves to broaden and melt compared to the real data. There is also a shift of the melting and solidification peaks to low and high temperatures (apparent hysteresis), respectively [21,22]. Thus low rates of heating and cooling were selected for this experiment: $0.05 \mathrm{~K} \cdot \mathrm{min}^{-1}$.

Two curves are presented for each material, (Figure 1a): the melting curve (heating from 0 to $22^{\circ} \mathrm{C}$ ) and the solidification curve (cooling from 22 to $0^{\circ} \mathrm{C}$ ). These curves represent the equivalent thermal capacity (heat capacity plus latent heat) of the materials studied. Considering the uncertainties of the heat flow $\left( \pm 0.2 \mu \mathrm{W}\right.$, constructor signal noise), scanning rate $\left( \pm 0.01 \mathrm{~K} \cdot \mathrm{min}^{-1}\right.$, smaller scanning rate of the apparatus) and mass sample $( \pm 0.5 \mathrm{mg}$ ) measures, the uncertainties measurement of the equivalent heat capacity and specific enthalpy are respectively estimated at $5 \%$ and $7 \%$.

These curves show that the melting and solidification peaks occur around $18^{\circ} \mathrm{C}$ and $14^{\circ} \mathrm{C}$, respectively, for all the samples studied. Hysteresis can be observed; the melting peak occurs at a temperature lower than the solidification peak. This is a common effect of many phase change materials and has already been observed in the literature $[16,22,23]$.

Furthermore, the enthalpy of the different samples is presented in Figure $1 \mathrm{~b}$. We recall that the enthalpy of a material can be deduced from its equivalent thermal capacity by the following equation:

$h(T)=\int_{0}^{T} c_{e q} d T$

The latent heat of melting and solidification are determined from these curves. The values obtained for the three materials tested are given in Table 2. The weight of the PCM content of the PU-PCM composites, $x$, is also presented. It is determined by the following relationship:

$x=\frac{L_{\text {composite }}}{L_{P C M}}$

With $\mathrm{L}_{\text {composite }}$ and $\mathrm{L}_{\mathrm{PCM}}$ being the latent heat average value of the composite material and of the pure PCM, respectively, measured by DSC (cf. Table 2 ).
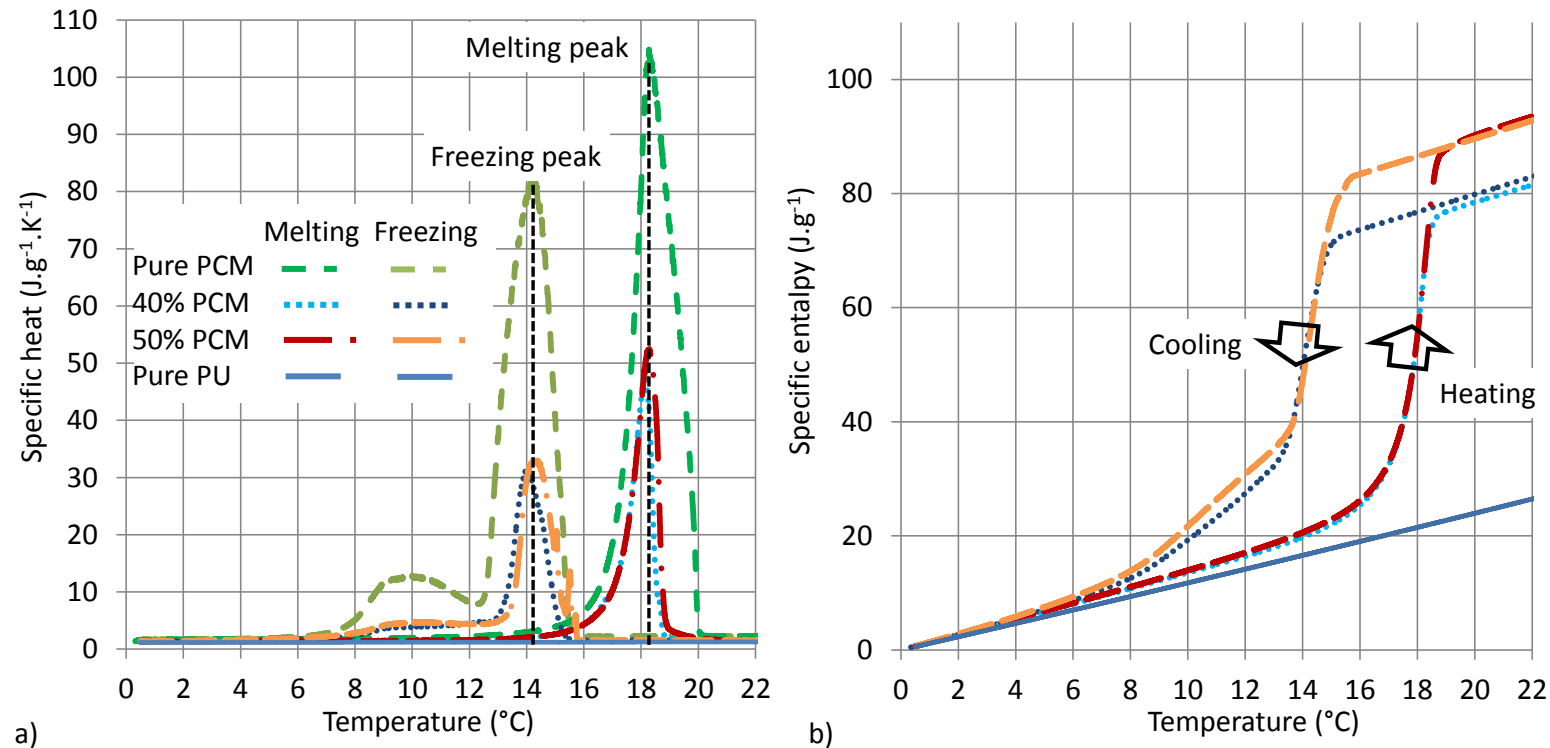

Figure 1 : a) Equivalent specific heat capacity of the pure PCM, the pure PU foam and the composites PU-PCM and. b) Enthalpy of the composites and the pure PU foam. 
Table 2: DSC study data.

\begin{tabular}{|c|c|c|c|c|c|c|c|}
\hline & $\begin{array}{c}\text { Mass } \\
(\mathrm{mg})\end{array}$ & $\begin{array}{l}\text { Temperature } \\
\text { of the } \\
\text { melting peak } \\
\left({ }^{\circ} \mathrm{C}\right) \\
\end{array}$ & $\begin{array}{c}\text { Temperature } \\
\text { of the } \\
\text { freezing peak } \\
\left({ }^{\circ} \mathrm{C}\right)\end{array}$ & $\begin{array}{l}\text { Latent heat } \\
\text { of melting, } \\
L_{m}(\mathrm{~J} / \mathrm{g})\end{array}$ & $\begin{array}{l}\text { Latent heat } \\
\text { of freezing, } \\
L_{f}(\mathrm{~J} / \mathrm{g})\end{array}$ & $\begin{array}{l}\text { Deduced } \\
\text { average } \\
\text { PCM mass } \\
\text { rate }\left(\%_{w}\right)\end{array}$ & $\begin{array}{c}\text { PCM mass rate } \\
\text { given by the } \\
\text { material seller }\left(\%_{w}\right)\end{array}$ \\
\hline $\begin{array}{c}\text { Pure PCM, } \\
\text { sample } 1\end{array}$ & 117 & \multirow{2}{*}{18.3} & \multirow{2}{*}{14.2} & $185.4 \pm 9.3$ & $186.4 \pm 9.3$ & \multirow{2}{*}{100} & \multirow{2}{*}{-} \\
\hline $\begin{array}{l}\text { Pure PCM, } \\
\text { sample } 2\end{array}$ & 124 & & & $188.1 \pm 9.4$ & $188.9 \pm 9.4$ & & \\
\hline $\begin{array}{c}\text { Composite } 1, \\
\text { sample } 1\end{array}$ & 47 & \multirow{2}{*}{18.1} & \multirow{2}{*}{14} & $49.8 \pm 2.5$ & $48.9 \pm 2.4$ & $26 \pm 3$ & \multirow{2}{*}{40} \\
\hline $\begin{array}{c}\text { Composite } 1, \\
\text { sample } 2\end{array}$ & 41 & & & $50.5 \pm 2.5$ & $50.7 \pm 2.5$ & $27 \pm 3$ & \\
\hline $\begin{array}{c}\text { Composite } 2 \text {, } \\
\text { sample } 1\end{array}$ & 64 & \multirow{2}{*}{18.3} & \multirow{2}{*}{14.3} & $60.1 \pm 3$ & $59.4 \pm 3$ & $32 \pm 3$ & \multirow{2}{*}{50} \\
\hline $\begin{array}{c}\text { Composite } 2, \\
\text { sample } 2\end{array}$ & 67 & & & $59.4 \pm 3$ & $58.7 \pm 2.9$ & $32 \pm 3$ & \\
\hline
\end{tabular}

For the two composite plates, the weight of the PCM content measured was lower than the expected values: $26 \%_{w}$ and $32 \%_{w}$ instead of $40 \%_{w}$ and $50 \%_{w}$, respectively, for composites 1 and 2 . The first explanation could be the inhomogeneity of the distribution of the microencapsulated PCM beads in the PU matrix. Similar results have been shown in the literature $[13,15]$. The authors explained this phenomenon by the segregation of the PCM beads between the top and bottom of the composite plates. Another explanation could be a possible loss of PCM beads during the elaboration of the samples tested by DSC. Indeed, in an SEM analysis of PU-PCM composite, Borreguero et al. [15] observed that the PCM microbeads were located in both the solid structure of the PU foam and the pores. The microbeads located in the foam pores may be lost during cutting of samples for the DSC study.

The small sample sizes used in the DSC measurements $(\approx 100 \mathrm{mg})$ therefore did not allow obtaining a representative measurement of the equivalent specific heat of the entire composite plate.

Thus, in order to determine the latent heat at the plate scale, a second experimental approach was applied. It is presented in $\S 0$.

\section{c) Thermal conductivity}

According to ISO 8301, the apparent thermal conductivity of different materials is measured with a conductimeter (NETZSCH HFM 436/3), in the temperature range of 5 to $35^{\circ} \mathrm{C}$ and an imposed temperature difference of $10^{\circ} \mathrm{C}$. The uncertainty on the thermal conductivity measurements is $5 \%$. 
The thermal conductivities of the plate of pure PU foam and of the two composite plates are presented as a function of temperature in Figure 2.

Note that the addition of PCM in the PU foam significantly increases its thermal conductivity. Thus its value was about 2 times higher for the composites than for the non-composite PU foam, ranging from $0.025 \mathrm{~W} \cdot \mathrm{m} \cdot \mathrm{K}^{-1}$ to about $0.05 \mathrm{~W} \cdot \mathrm{m} \cdot \mathrm{K}^{-1}$.

Furthermore, it was also observed that the thermal conductivity of the composite increased as a function of the proportion of PCM (average rise of 11.5\%) when the weight of the PCM content indicated by the material vendor increased from $40 \%_{\mathrm{w}}$ to $50 \%_{\mathrm{w}}$.

Finally, the thermal conductivities of the composite plates did not evolve significantly with temperature. In the $5-35^{\circ} \mathrm{C}$ range, the average conductivity was $0.046 \mathrm{~W} \cdot \mathrm{m}^{-1} \cdot \mathrm{K}^{-1}$ and $0.05 \mathrm{~W} \cdot \mathrm{m}^{-1} \cdot \mathrm{K}^{-1}$ for composite plates 1 and 2 , respectively.

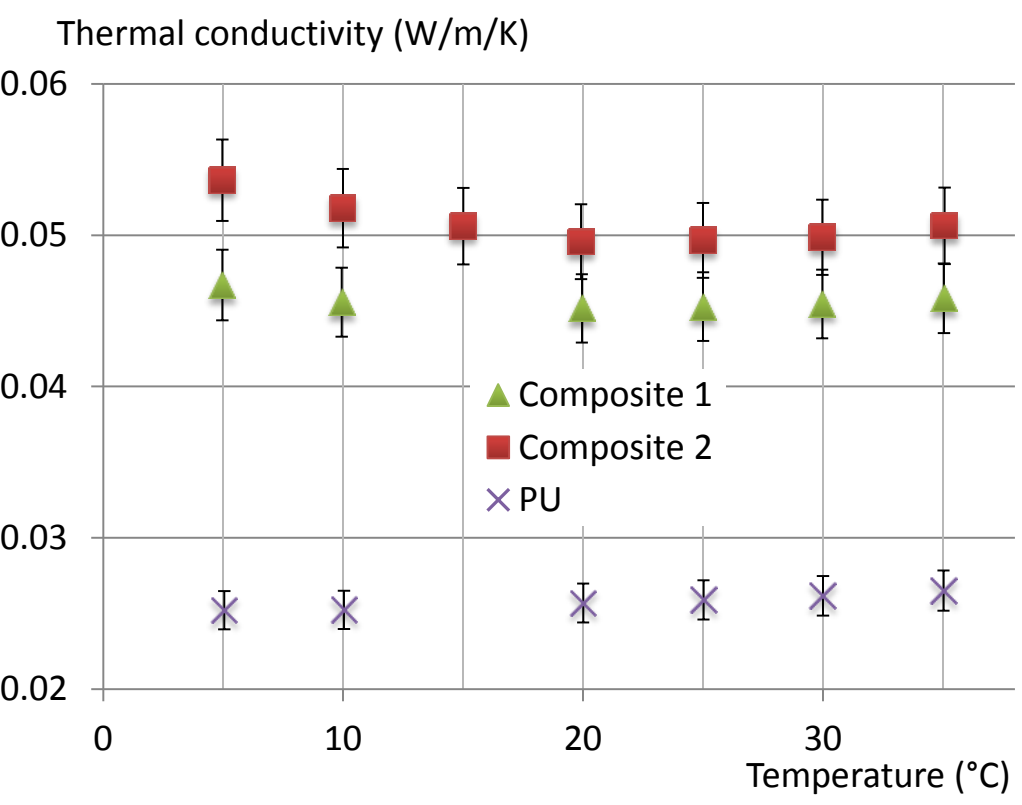

Figure 2: Thermal conductivities of the PU and composites (PU-PCM) plates

\subsection{Experimental device for the thermal study of insulating plates}

The aim of these experiments was to characterize transient heat transfer in single-layer and multilayer insulating plates. The samples were placed between two isothermal copper plates. These exchangers were crossed by a brine circuit whose temperatures were imposed by thermostatically controlled baths. A schematic representation of the device is shown in Figure 3.

Measurements were performed on monolayer plates of PU-PCM composite and three-layer plates consisting of a $2 \mathrm{~cm}$ thick layer of PU-PCM inserted between two layers of PU foam. They were insulated with $4 \mathrm{~cm}$ of PU to reduce thermal exchanges on the lateral faces.

To observe the thermal response of the configurations tested, type $\mathrm{K}$ thermocouples and $10 \times 10$ $\mathrm{cm}^{2}$ fluxmeters (Captec) were arranged on each of copper/material plate interfaces, as shown in Figure $3\left(T_{\mathrm{w} 1}, T_{\mathrm{w} 2}, \Phi_{1}\right.$ and $\left.\Phi_{2}\right)$. The diameter of the thermocouples was $0.3 \mathrm{~mm}$ and the fluxmeters were $0.4 \mathrm{~mm}$ thick. The uncertainties on the temperature and heat flow measurements were $\pm 0.5^{\circ} \mathrm{C}$ and $\pm 3 \%$, respectively, of the measured value. 
As shown in Figure 3, for the three-layer configuration study, thermocouples were also placed at the interfaces of the PU/composite "PU-PCM" ( $\mathrm{T}_{\mathrm{PCM} 1}$ and $\left.\mathrm{T}_{\mathrm{PCM} 2}\right)$.

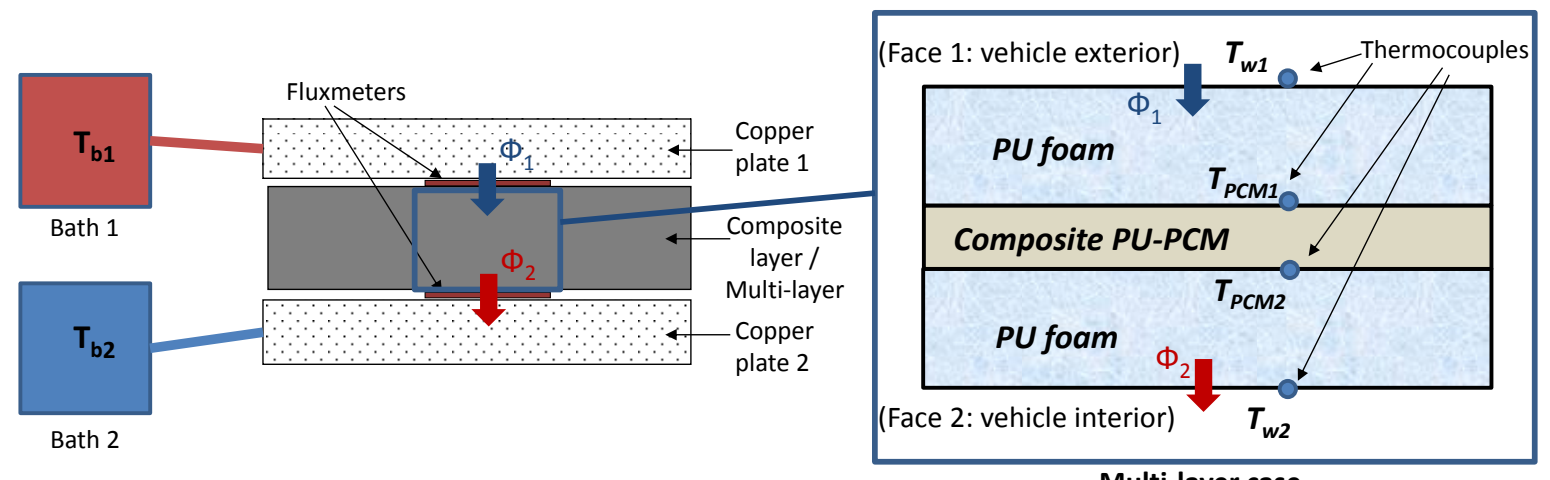

Multi-layer case

Figure 3 : Schematic description of the experimental device.

\subsection{Numerical model}

A dynamic 1D model of heat transfers within a three-layer wall (containing two PU layers and a "PU-PCM" layer, cf. Figure 3) was developed. This model was solved with the finite element method and implemented in the COMSOL software.

The model developed is based on an enthalpy balance within the multilayer wall. Thus, according to the heat conduction equation, the energy balance can be written as an enthalpy formulation:

$\rho \frac{\partial h}{\partial t}=\nabla \cdot(\lambda(T) \nabla T)$

with $\rho$ being the density, $\lambda$ the thermal conductivity and $h$ the specific enthalpy.

The specific enthalpies of the PU $\left(h_{\mathrm{PU}}\right)$ and the PCM $\left(\mathrm{h}_{\mathrm{PCM}}\right)$ were determined with the DSC method (§2.1.2). For composite materials, by additivity, their enthalpy is equal to the sum of the enthalpies of these constituents, as in:

$h_{\text {composite }}=(1-x) h_{P U}+x h_{P C M}$

with $\mathrm{x}$ being the PCM mass content in the composite, determined with the experimental device for plate studies (§0).

Moreover, in the model, the PCM enthalpy hysteresis between the fusion and the solidification phases is only considered when the phase change is complete $\left(T>18.3^{\circ} \mathrm{C}\right.$ for melting and $T<6^{\circ} \mathrm{C}$ for freezing). Indeed this phenomenon was confirmed during experiments conducted with DSC. Thus the enthalpy of a sample of composite 2 was determined (cf. §2.1.2b) during heating (PCM melting) and then cooling ( $\mathrm{PCM}$ freezing), for three different temperature ranges $\left(0-22^{\circ} \mathrm{C}, 0-19^{\circ} \mathrm{C}\right.$ and $0-17^{\circ} \mathrm{C}$. As shown in Figure 4, no enthalpy hysteresis between the fusion and the solidification phases occurs when the PCM of the composite is partially melted $\left(0-17^{\circ} \mathrm{C}\right.$ case). 


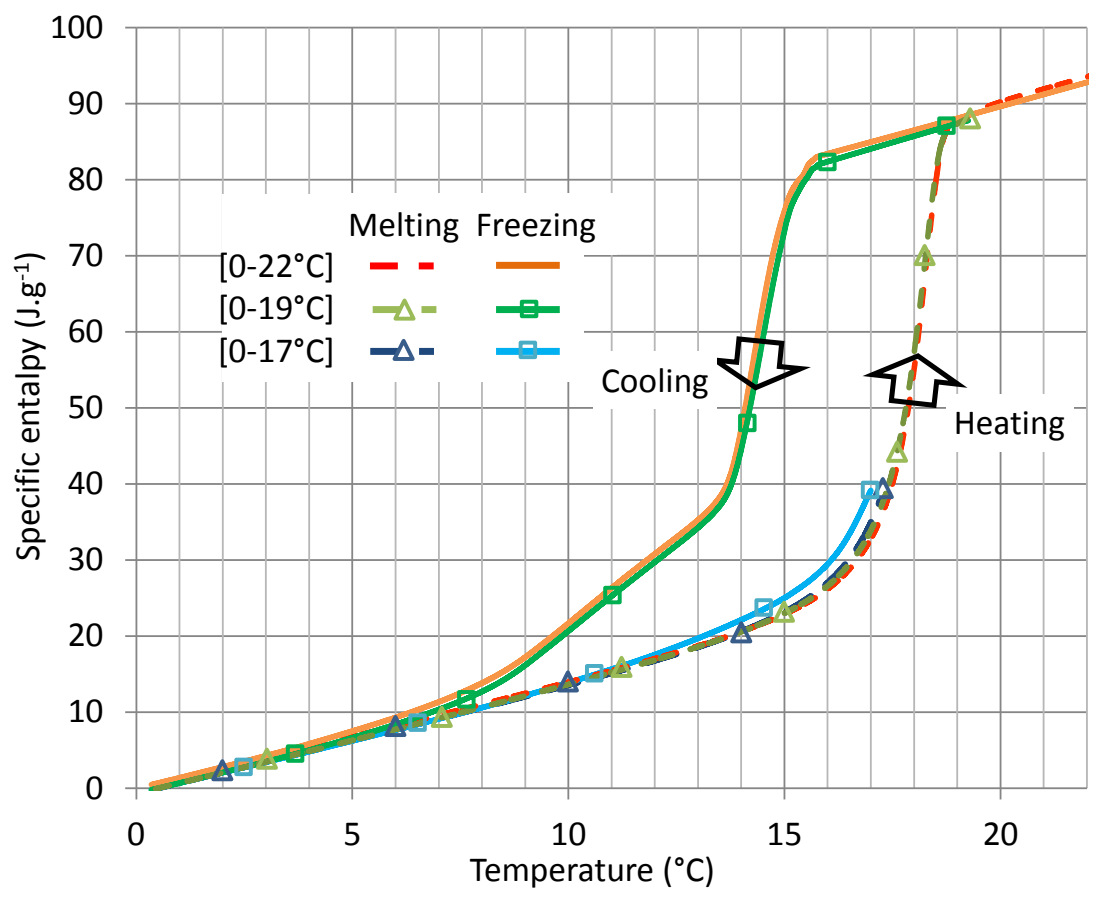

Figure 4: Enthalpy of the composite 2 as function of the temperature, determined by DSC experiment using three different temperature ranges $\left(\left[0 ; 22{ }^{\circ} \mathrm{C}\right],\left[0 ; 19^{\circ} \mathrm{C}\right]\right.$ and $\left.\left[0 ; 17^{\circ} \mathrm{C}\right]\right)$.

The energy balance equation is completed with the following boundaries and initial conditions:

- The temperatures of the isothermal surfaces (face 1 ) and (face 2 ) are imposed.

- The initial temperature and enthalpy are chosen as uniform throughout the wall.

\section{Results and discussion}

\subsection{Study of "PU-PCM" composite plates}

This part is dedicated to the experimental and numerical study of the "PU-PCM" plates containing $40 \%_{w}$ (Composite 1 ) and $50 \%_{w}$ (Composite 2 ) of phase change material.

\subsubsection{Latent heat of phase change}

The latent heat of fusion and solidification at the composite plate scale was determined using the experimental apparatus described in \$2.2. The composite plate was heated and then cooled over the temperature range $\left[2^{\circ} \mathrm{C}-30^{\circ} \mathrm{C}\right]$.

The temperatures and the heat flux densities measured during the test of Composite plate 1 are plotted in Figure 5. Initially the hot and cold cooper plates are held at a constant temperature $\left(T_{\text {ini }} \approx 2^{\circ} \mathrm{C}\right)$, then heated to $30^{\circ} \mathrm{C}$ until reaching thermal equilibrium, i.e. the sum of the heat flux densities crossing composite faces 1 and 2 is zero, and finally cooled again to $2^{\circ} \mathrm{C}$.

From these measurements the latent heats and the PCM mass rates are determined by integrating the heat flow density measured by the two flow meters between the two equilibrium states at $2^{\circ} \mathrm{C}$ and $30^{\circ} \mathrm{C}[24]$ :

$Q=\frac{1}{\rho \cdot e} \int\left(\phi_{1}+\phi_{2}\right) \cdot d t=\Delta h_{\text {composite }}$ 
With $\phi_{1}$ and $\phi_{2}$ the heat flow density at the composite boundary, $\phi_{i}$ is positive when the heat flow enters within the wall and negative as it exits; $e$ is the thickness of the composite wall and $\rho$ its density.

From this enthalpy variation and using the enthalpy of the pure PCM and the pure PU (determined by DSC, Table 2), it is then possible to estimate the mass rate of PCM contained in the composite plate:

$x=\frac{\Delta h_{\text {composite }}-\Delta h_{P U}}{\Delta h_{P C M}-\Delta h_{P U}}$

with $\Delta h_{i}=\int_{T=2}^{T=30} h_{i} d T$

Finally, the latent heat is obtained using the following relation:

$L_{\text {composite }}=x L_{P C M}$

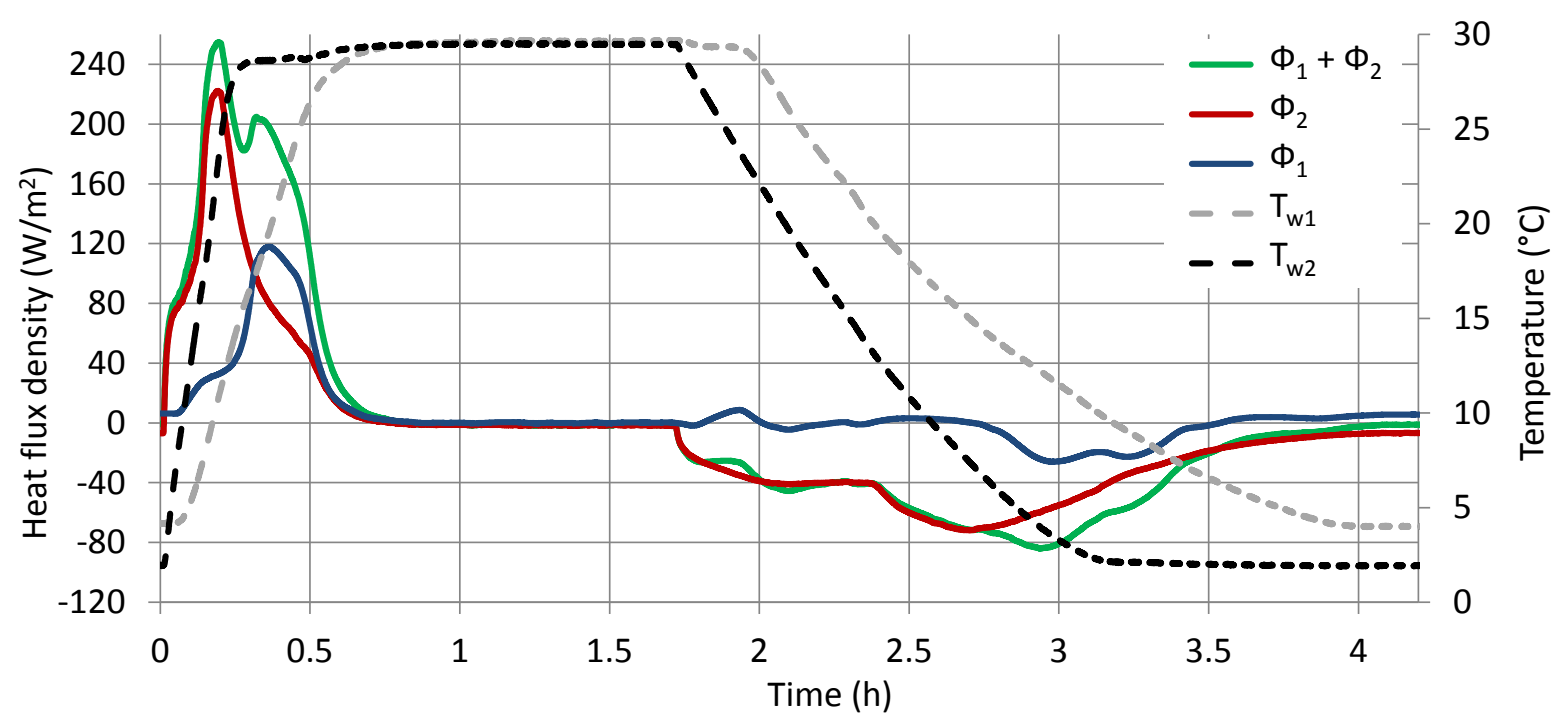

Figure 5: Heat flux densities and temperatures measured at the walls of the plate of composite $1\left(40 \%_{w}\right.$ de PCM).

Using these experiments and equations (3)-(5), the latent heat and the PCM rate contained in composite plates 1 and 2 were determined. The values are summarized in Table 3 . The average weight of the PCM content in the plates was $35.3 \pm 4.6 \%_{w}$ and $43 \pm 5.5 \%_{w}$ for composites 1 and 2 , respectively. This represents average latent heats of $65.6 \pm 11.8 \mathrm{~J} / \mathrm{g}$ and $80.2 \pm 14.2 \mathrm{~J} / \mathrm{g}$. Taking into account uncertainties, these values are close to the expected values (given by the material vendor): $40 \%_{\mathrm{w}}$ and $50 \%_{\mathrm{w}}$ for composites 1 and 2 respectively. Moreover, these values were higher than the DSC measures, $26 \%_{\mathrm{w}}$ and $32 \%_{\mathrm{w}}$ for composites 1 and 2, respectively. As mentioned above, this difference could be due to inhomogeneity of the distribution of PCM microbeads at the local scale, within the composite material. This caused erroneous latent heat measurements for small sized samples (50-100 mg for the DSC experiment, see Table 2), and losses of PCM nodules during sampling.

Table 3: Latent heats and mass rates of PCM in the samples of composite 1 and 2 measured with the experimental device and the DSC.

\begin{tabular}{|l|c|c|c|c|c|c|}
\hline & $\mathrm{L}_{\mathrm{m}}(\mathrm{J} / \mathrm{g})$ & $\mathrm{L}_{\mathrm{f}}(\mathrm{J} / \mathrm{g})$ & $\begin{array}{c}\text { Experimental } \\
\text { mass rate of } \\
\mathrm{PCM}(\text { melting) } \\
\left(\%_{\mathrm{w}}\right)\end{array}$ & $\begin{array}{c}\text { Experimental } \\
\text { mass rate of } \\
\mathrm{PCM}(\text { freezing) } \\
\left(\%_{\mathrm{w}}\right)\end{array}$ & $\begin{array}{c}\text { PCM mass } \\
\text { rate } \\
\text { measured } \\
\text { by DSC }\left(\%_{\mathrm{w}}\right)\end{array}$ & $\begin{array}{c}\text { PCM mass rate } \\
\text { given by } \\
\text { material seller } \\
\left(\%_{\mathrm{w}}\right)\end{array}$ \\
\hline Composite 1 & $62.9 \pm 11.6$ & $68.2 \pm 12$ & $33.9 \pm 4.6$ & $36.6 \pm 4.6$ & $27 \pm 3$ & 40 \\
\hline Composite 2 & $79.1 \pm 14.1$ & $80.9 \pm 14.3$ & $42.6 \pm 5.5$ & $43.4 \pm 5.4$ & $32 \pm 3$ & 50 \\
\hline
\end{tabular}




\subsection{2. “Refrigerated vehicle" scenario}

Here we study the scenario of a refrigerated vehicle wall. In this case the insulation of the isothermal compartment is provided conventionally by $6 \mathrm{~cm}$ of PU foam [24,25].

The test protocol consisted in imposing the temperature changes undergone by an isothermal compartment during a typical day of use at the wall boundaries studied. This $24 \mathrm{~h}$ scenario comprised the three steps described below and shown schematically in Figure 6:

- The first step, lasting $8 \mathrm{~h}$, corresponded to the cooling that takes place at night in the isothermal compartment of the vehicle: "cooling period". During this step, one face of the wall (face 1) was set at $2^{\circ} \mathrm{C}$ (internal temperature of the vehicle) and the second (face 2) was set at $10^{\circ} \mathrm{C}$ (external temperature: garage).

- The second step was the delivery round period ("day period"). It was assumed that the outdoor temperature (face 2) gradually increases from $10^{\circ} \mathrm{C}$ to $30^{\circ} \mathrm{C}$ in 2 hours (start of day). This temperature then remains at $30^{\circ} \mathrm{C}$ for $4 \mathrm{~h}$ after which gradually decreases from $30^{\circ} \mathrm{C}$ to $10^{\circ} \mathrm{C}$ in 2 hours (end of day). Throughout this period of the day, the inner face temperature (face 1 ) was imposed at $2^{\circ} \mathrm{C}$.

- Finally, the third step corresponded to the stopping of the refrigerated vehicle and its shutdown period in the garage (doors open). Thus the two faces of the insulated wall were brought to $10^{\circ} \mathrm{C}$ and then left at this temperature for $8 \mathrm{~h}$, after which a new cycle began.

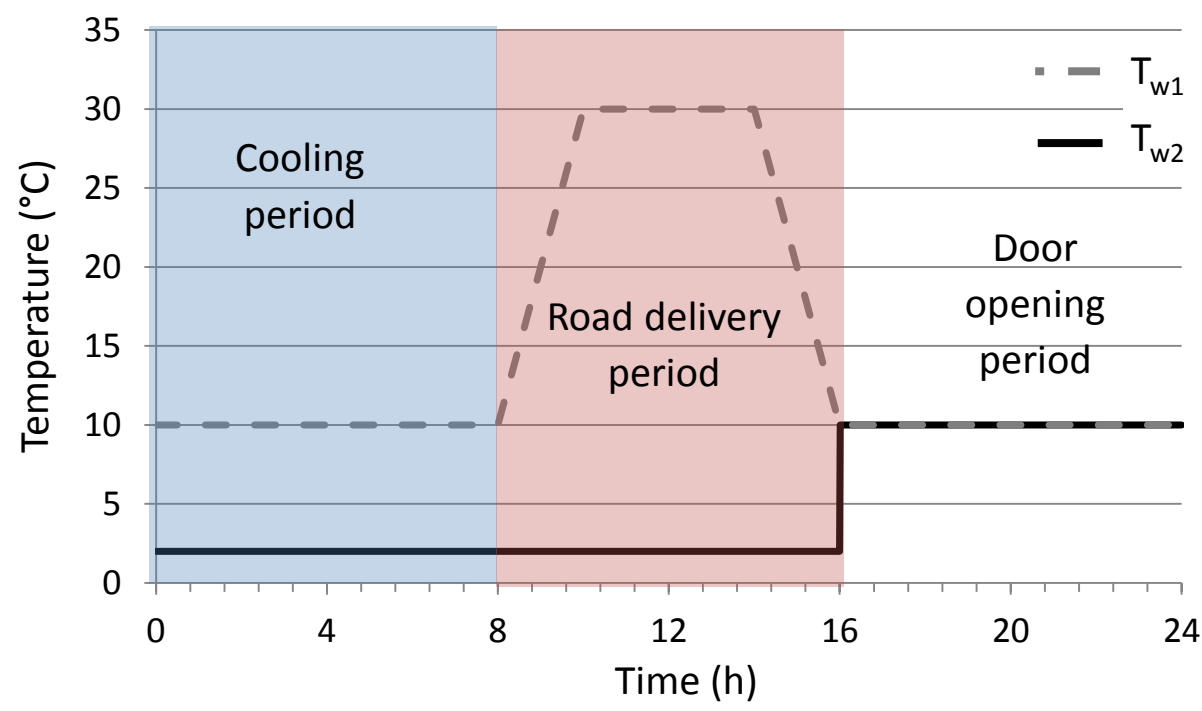

Figure 6 : "Refrigerated vehicle" scenario: imposed temperatures at the two faces of the insulating wall.

\subsubsection{Experimental results and simulation}

For the "refrigerated vehicle" scenario, Figure 7 shows an experimental and simulated (cf. §2.3) comparison of the heat flux densities and temperatures (that correspond to the model boundary conditions) at each face of Composite plate 2.

Due to these values, the difference between the experimental and numerical heat flux densities was rather low, especially during steady state periods (2-8h; $17-24 \mathrm{~h})$ : at $4 \mathrm{~h}$ it was $0.7 \%$ and $1.7 \%$ for $\Phi_{1}$ and $\Phi_{2}$, respectively. A slight deviation was observed during sudden changes of the imposed temperatures $(8-10 \mathrm{~h} ; 14-16 \mathrm{~h})$. However, the modeled results are acceptable: at $10 \mathrm{~h}$ the deviation was $8 \%$ and $8.5 \%$ for $\Phi_{1}$ and $\Phi_{2}$, respectively. 
These results demonstrate that the 1D model predicts the heat flux densities at each wall boundary satisfactorily. Thus this tool is relevant for the purpose of this paper which is to study the thermal response of a multilayer wall containing PU-PCM layers.

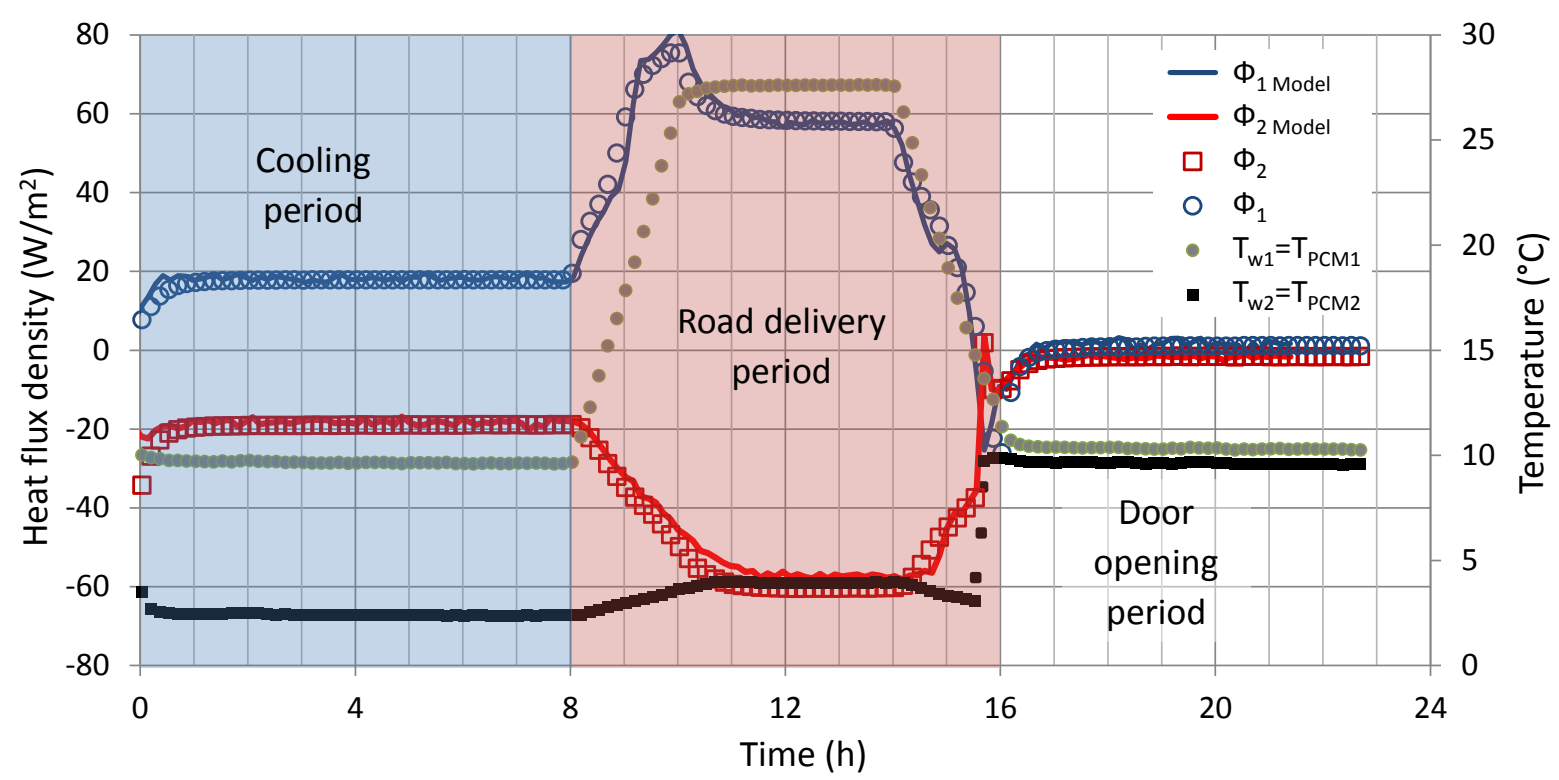

Figure 7 : "Refrigerated vehicle" scenario: experimental and numerical thermal response of insulated composite plate 2 $\left(43 \%_{w}\right.$ PCM).

A parametric study was carried out with the 1D model using the same scenario and composite plate (i.e. "refrigerated vehicle" scenario and Composite plate 2). Thus the influences of the latent heat of fusion / solidification and of the composite thermal conductivity were studied. Values of $\pm 10 \%$ compared to the experimental results (cf. §2.1.2 and §3.1) were used in the simulations.

Figure 8 presents a comparison of the simulated heat flux densities crossing face 2 (corresponding to the vehicle interior face). We first note that, logically, the heat flux density $\phi_{2}$ is influenced by the thermal conductivity of the composite layer, especially during the "cooling" and "door opening" periods (corresponding to steady state periods). Thus, during these periods, a change of $\pm 10 \%$ of the thermal conductivity corresponds to a change of $\pm 10 \%$ of the heat flux densities. However, the impact of the thermal conductivity is less marked when the outdoor temperature (temperature of face 2) gradually increases/decreases $(t=8-10 \mathrm{~h} / 14-16 \mathrm{~h})$. Furthermore, Figure 8 shows that it does not have a significant impact on the heat flux $\phi_{2}$ for the range of the PCM latent heat value studied. Thus, for the whole scenario, the variation of energy crossing face 2 between the reference case and the cases with $\pm 10 \%$ of the PCM latent heat value is less than $0.1 \%$. 


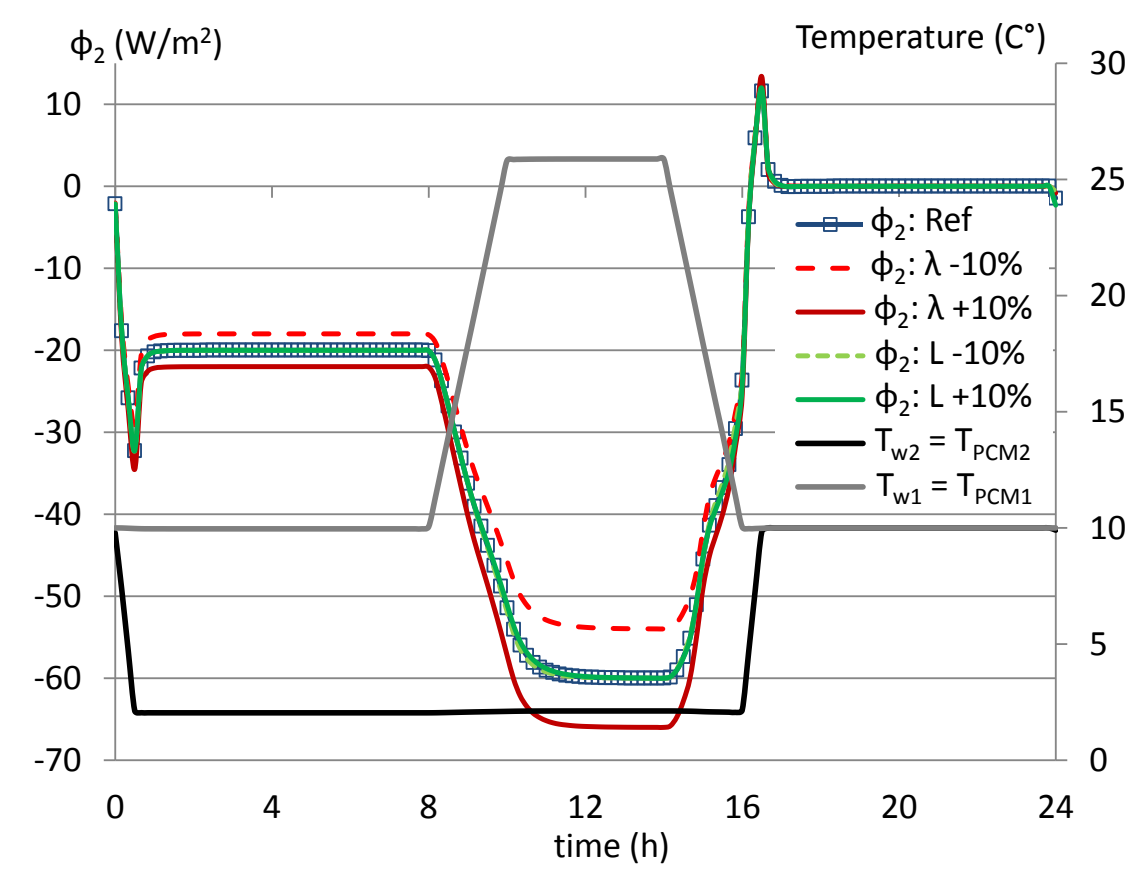

Figure 8: Parametric study using the 1D model: influence of the thermal conductivity $(\lambda)$ and latent heat (L) of Composite plate 2 during the "vehicle refrigeration" scenario.

\subsection{Multilayer wall study}

Different multilayer wall configurations with a total thickness of $6 \mathrm{~cm}$ were tested. In the three cases studied, a "PU-PCM" layer of composite 2 (containing 43\% ${ }_{w}$ PCM) $2 \mathrm{~cm}$ thick was inserted between two layers of polyurethane foam with a thickness ranging between 1 and $3 \mathrm{~cm}$. A change in the thickness of each layer of PU impacted the position of the composite within the wall (Table 4).

These configurations were tested by applying the "refrigerated vehicle" scenario described previously (§3.1.2). We recall that two thermocouples were inserted on each side of the "PU-PCM" layer $\left(\mathrm{T}_{\mathrm{PCM} 1}\right.$ and $\mathrm{T}_{\mathrm{PCM} 2}$ ) (Figure 3 ). Moreover, it is important to note that before the first experimental cycle, the wall tested was brought to thermal equilibrium at $10^{\circ} \mathrm{C}$. Furthermore, for the numerical studies, two cycles were carried out but only the second cycle is presented in this paper.

Table 4: Composition of the multilayer walls studied.

\begin{tabular}{|c|l|c|l|}
\hline Case & Layer 1 (vehicle interior) & Layer 2 (center) & Layer 3 (vehicle exterior) \\
\hline 1 & $1 \mathrm{~cm}$ of PU & $2 \mathrm{~cm}$ of composite 2 & $3 \mathrm{~cm}$ of PU \\
\hline 2 & $2 \mathrm{~cm}$ of PU & $2 \mathrm{~cm}$ of composite 2 & $2 \mathrm{~cm}$ of PU \\
\hline 3 & $3 \mathrm{~cm}$ of PU & $2 \mathrm{~cm}$ of composite 2 & $1 \mathrm{~cm}$ of PU \\
\hline 4 & $3 \mathrm{~cm}$ of PU & $1.5 \mathrm{~cm}$ of composite 2 & $1.5 \mathrm{~cm}$ of PU \\
\hline 5 & $4 \mathrm{~cm}$ of PU & $1.5 \mathrm{~cm}$ of composite 2 & $0.5 \mathrm{~cm}$ of PU \\
\hline 6 & $3.5 \mathrm{~cm}$ of PU & $2 \mathrm{~cm}$ of composite 2 & $0.5 \mathrm{~cm}$ of PU \\
\hline Ref & $6 \mathrm{~cm}$ of PU & - & - \\
\hline
\end{tabular}

\subsubsection{Study of case 1}

Two successive cycles of the "refrigerated vehicle" scenario (\$3.1.2) were applied to the threelayer insulating wall corresponding to case 1 (Table 4). The temperatures and the heat flux densities at the interfaces are shown respectively in Figure $9 a$ and $b$. 
We observed that the "cooling period" (until the $8^{\text {th }}$ hour) was sufficiently long to reach the thermal equilibrium of the composite layer and allow solidifying the PCM therein (composite layer temperature lower than $7^{\circ} \mathrm{C}$ ). However, we noted that the temperature of the composite layer did not exceed $14^{\circ} \mathrm{C}$ during the experiment. This temperature was below the melting temperature of the PCM (see Figure 1). In this configuration the PCM did not start melting. Therefore the location of the composite layer in the wall was not optimal.

Thus, in order to improve the performance of the insulating wall, particularly by exploiting its heat storage capacity, it could be interesting to move the layer of "PU-PCM" composite toward the outside of the wall ("hot" part): cases 2 and 3 (see Table 4).

Furthermore, we noted that the thermal response of the multilayer wall to the imposed scenario was reproducible. The two cycles performed presented similar results.

Finally, the comparison of experimental and simulated data showed good agreement between the experimental results and those obtained from the model (Figure 9). Thus the temperatures within the plate and the heat flux densities were well simulated by the model.

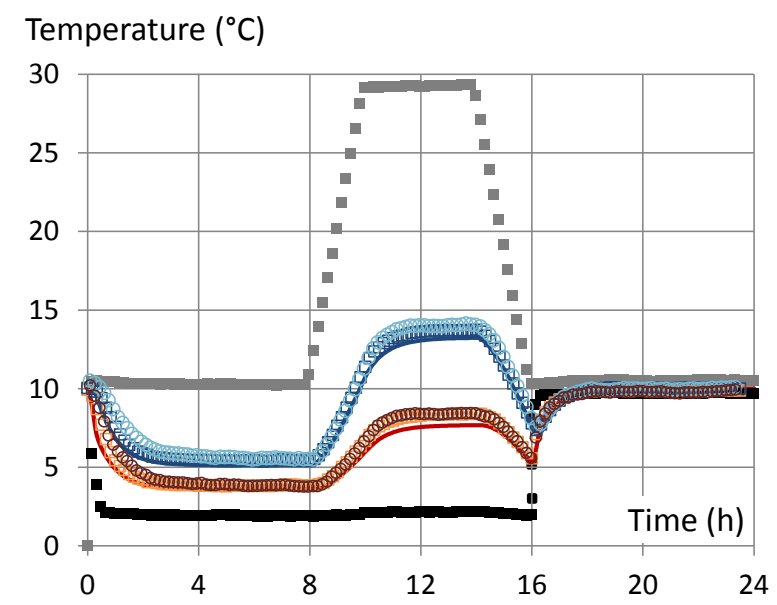

a)

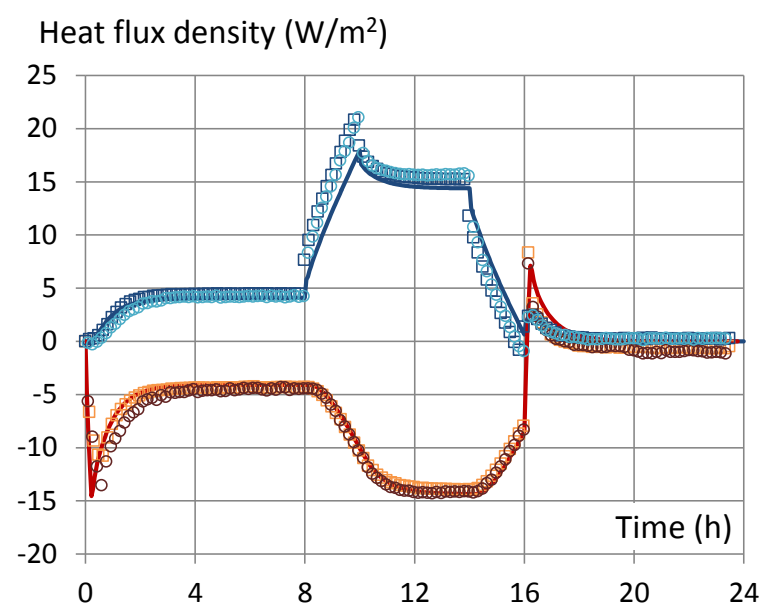

b)

\begin{tabular}{|c|c|c|c|}
\hline & \multicolumn{3}{|c|}{$\mathrm{T}_{\mathrm{PCM} 1} / \phi_{1} \mathrm{~T}_{\mathrm{PCM} 2} / \phi$} \\
\hline & Cycle 1 & 口 & \\
\hline & Cycle 2 & $\circ$ & 0 \\
\hline & Model & - & - \\
\hline
\end{tabular}

Figure 9 : Cycling of the case 1 and comparison with the model.

\subsubsection{Experimental comparison of cases 1 and 2}

Figure 10 shows that during the "road delivery period" the surface temperatures of the "PU-PCM" layer tend toward $12^{\circ} \mathrm{C}$ and $17^{\circ} \mathrm{C}$ in case 2 versus only $8^{\circ} \mathrm{C}$ and $14^{\circ} \mathrm{C}$ for case 1 . Thus the PCM melted partially between $14^{\circ} \mathrm{C}$ and $19^{\circ} \mathrm{C}$ (see Figure 1 ) in case 2 and did not begin in case 1 . Compared to case 1 , the result was a decrease of the outgoing heat flux from the inner face of the insulating wall (face 2: $\phi_{2}$ ) despite an increase in heat flux penetrating the wall from the outer face (face 1: $\phi_{1}$ ) (see Figure 10b).

The heat crossing face 2 during the "road delivery period" (corresponding to the heat penetrating into an isothermal compartment composed of the multilayer wall), calculated using relation (8), decreased from $89.4 \mathrm{Wh} / \mathrm{m}^{2}$ in case 1 to $82.5 \mathrm{Wh} / \mathrm{m}^{2}$ in case 2 . Thus the PCM layer fulfilled its role by limiting the penetration of the heat flux into the isothermal compartment during this period. 
$E=\int \phi_{2} d t$

with $E$ and $\phi_{2}$ being the heat and the heat flux density, respectively, crossing the inside face of the insulating wall (face 2 ) during the "road delivery period".

Furthermore, Figure 10b shows that in steady state (end of the "cooling period" and "door opening period"), the heat flux densities crossing the wall of cases 1 and 2 are similar: i.e. the thermal conductivities of the multilayer wall used in cases 1 and 2 are close.
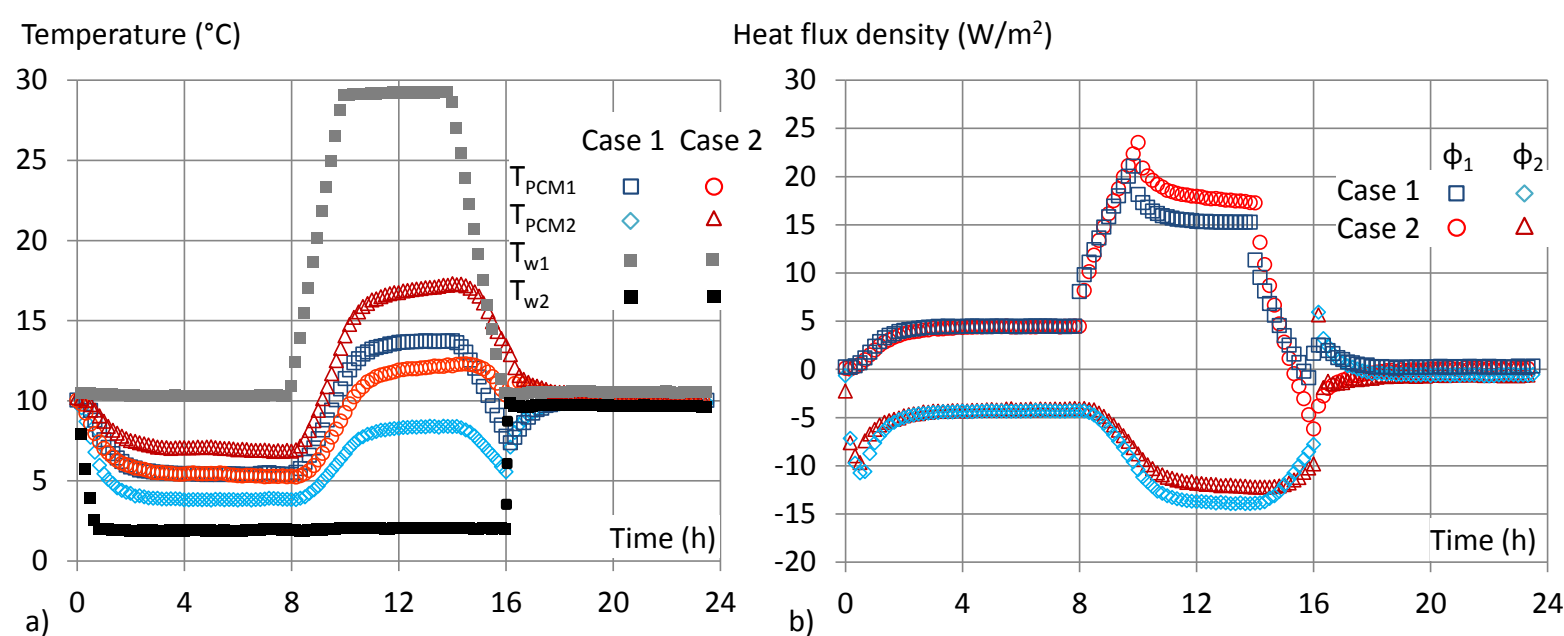

Figure 10 : "Refrigerated vehicle" scenario: experimental thermal response of the multilayer wall of the cases 1 and 2.

\subsubsection{Numerical study}

Figure 11 presents the simulated outgoing heat flux densities from the inner face of the insulating wall $\left(\phi_{2}\right)$ during the "road delivery period" and for the four cases of Table 4 . Case 4 corresponds to a reference wall composed of $6 \mathrm{~cm}$ thick polyurethane.

We note that the composite layer fulfils its role of cold storage and decreases the heat flux density $\phi_{2}$. When the "PU-PCM" layer is positioned far from the outer face of the vehicle insulating wall (cases 1 and 2), the effect of the latent heat is limited to the two first hours of the "road delivery period". Indeed, the temperature of the PCM contained in the composite layer is too low for it to melt completely. Moreover, since the thermal conductivity of PU is lower than that of the composite layer, the heat flux density quickly becomes higher than the reference case.

On the contrary, when the "PU-PCM" layer is placed close to the outer face of the vehicle wall (case $3)$, the heat flux density $\phi_{2}$, becomes lower than that of the reference wall for most of the "road delivery period". This heat flux is higher than that of the reference case only for the last two hours of the "road delivery period". 


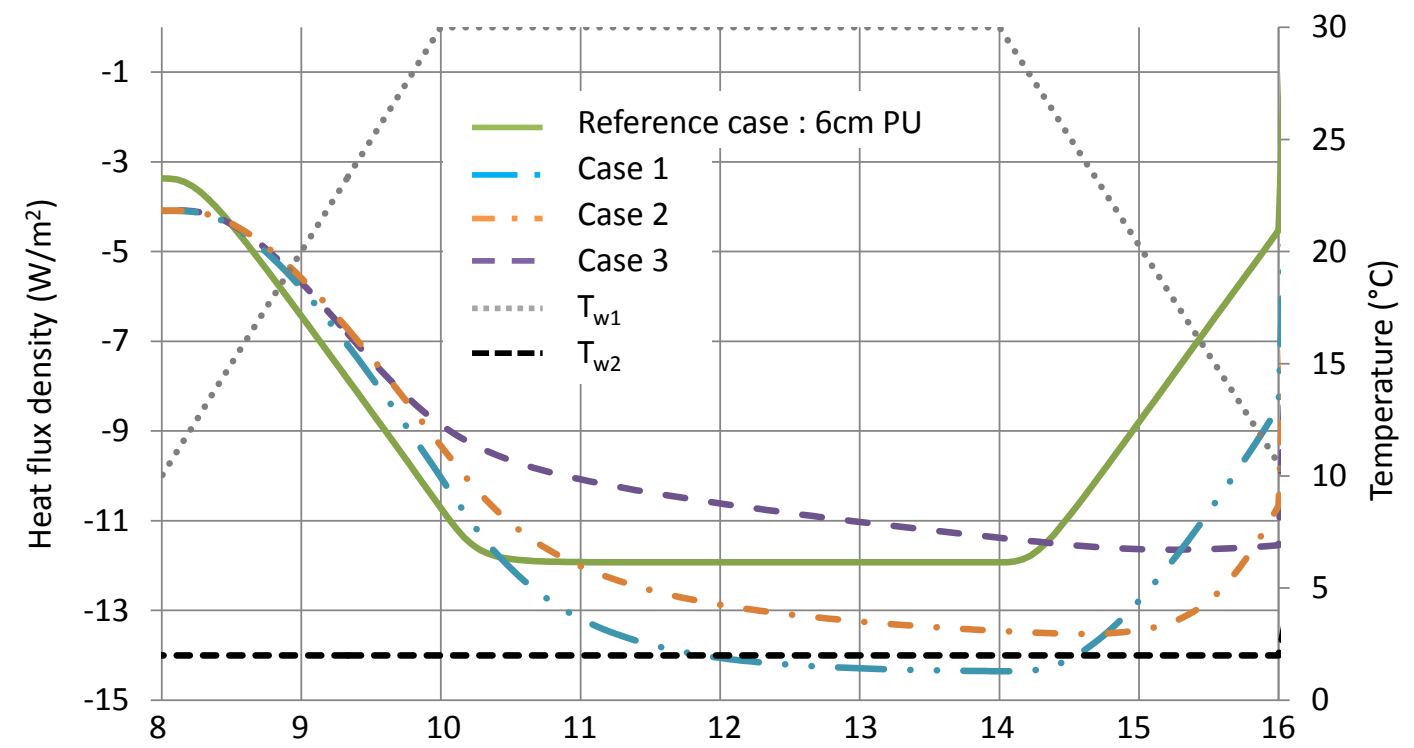

Figure 11 : Numerical heat flux densities at face 1 for the reference case and cases 1,2 and 3, during the "road delivery period" of the "refrigerated vehicle" scenario.

Furthermore, Figure 12 shows that the temperatures of each face of the composite layer of case 3 are not stabilized at the end of the "road delivery period". Thermal equilibrium is therefore not reached. Moreover, during this period the temperature of the composite layer did not exceed $18^{\circ} \mathrm{C}$. The PCM phase change is therefore not complete (see Figure 1). It is therefore possible to improve the size (case 5) and location (case 6) of the PU-PCM layer, in particular to maximize the PCM phase change rate.

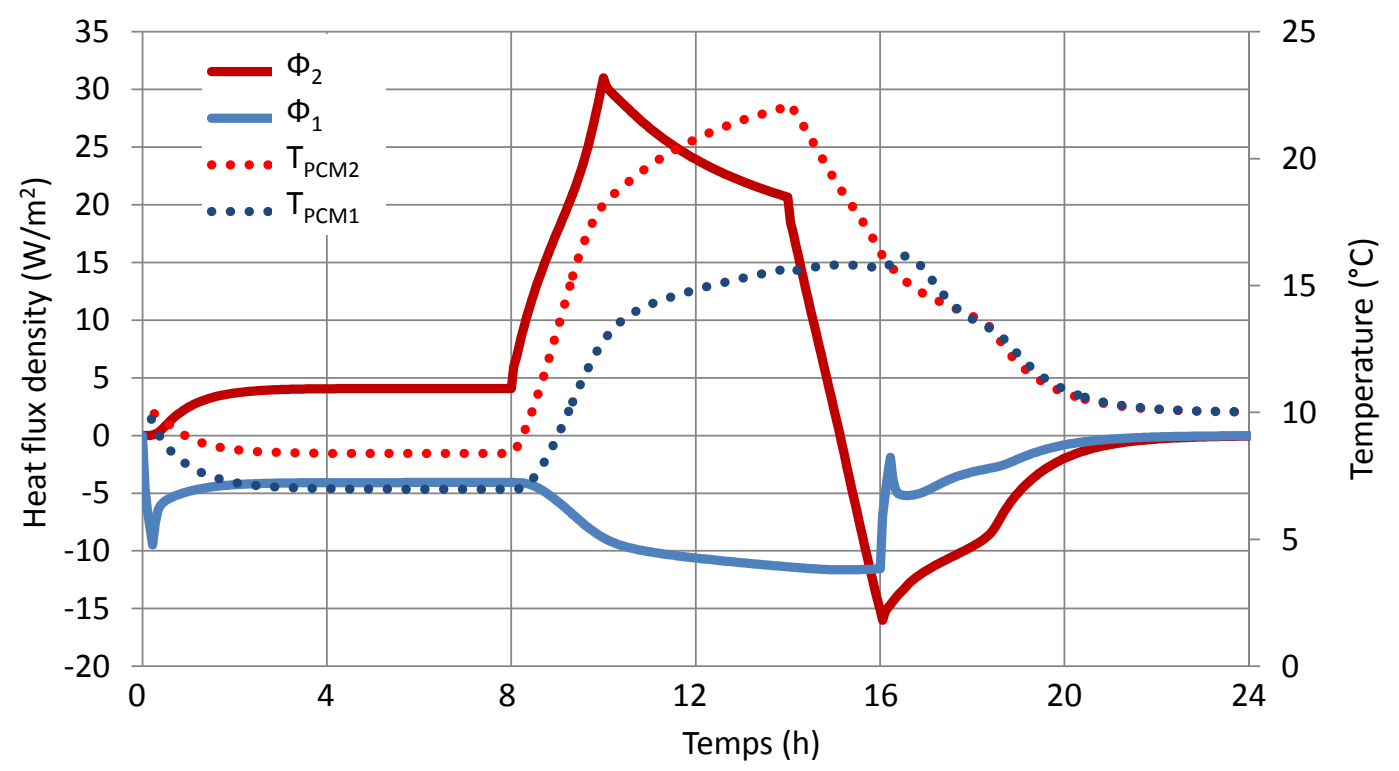

Figure 12 : Case 3 studied with the "refrigerated vehicle" scenario: numerical heat flux densities of faces 1 and 2 and composite face temperatures.

Finally, the heat received by the isothermal compartment during the "road delivery period" (see equation (8)) for the different cases studied is presented in Figure 13. 
Logically, the cases where the composite layer was placed far from the outer face of the multilayer wall (cases 1 and 2) presented substantially more energy penetrating into the isothermal enclosure than the reference case. However, case 2 was more favorable than case 1.

Furthermore, we note that cases 3 to 6 slightly reduced heat entering the isothermal compartment, by from about $0.3 \%$ to $4.1 \%$, respectively, compared to the reference case. This shows that it is important to optimize the position and thickness of the composite layer to reduce the energy demand of cold production during the "road delivery period". The optimization of these parameters is in progress. However, Figure 13 allows highlighting optimization tracks. Thus Figure 13we observe that, for the studied PCM material, the location of the composite layer has a greater impact to reduce the energy demand than its thickness.

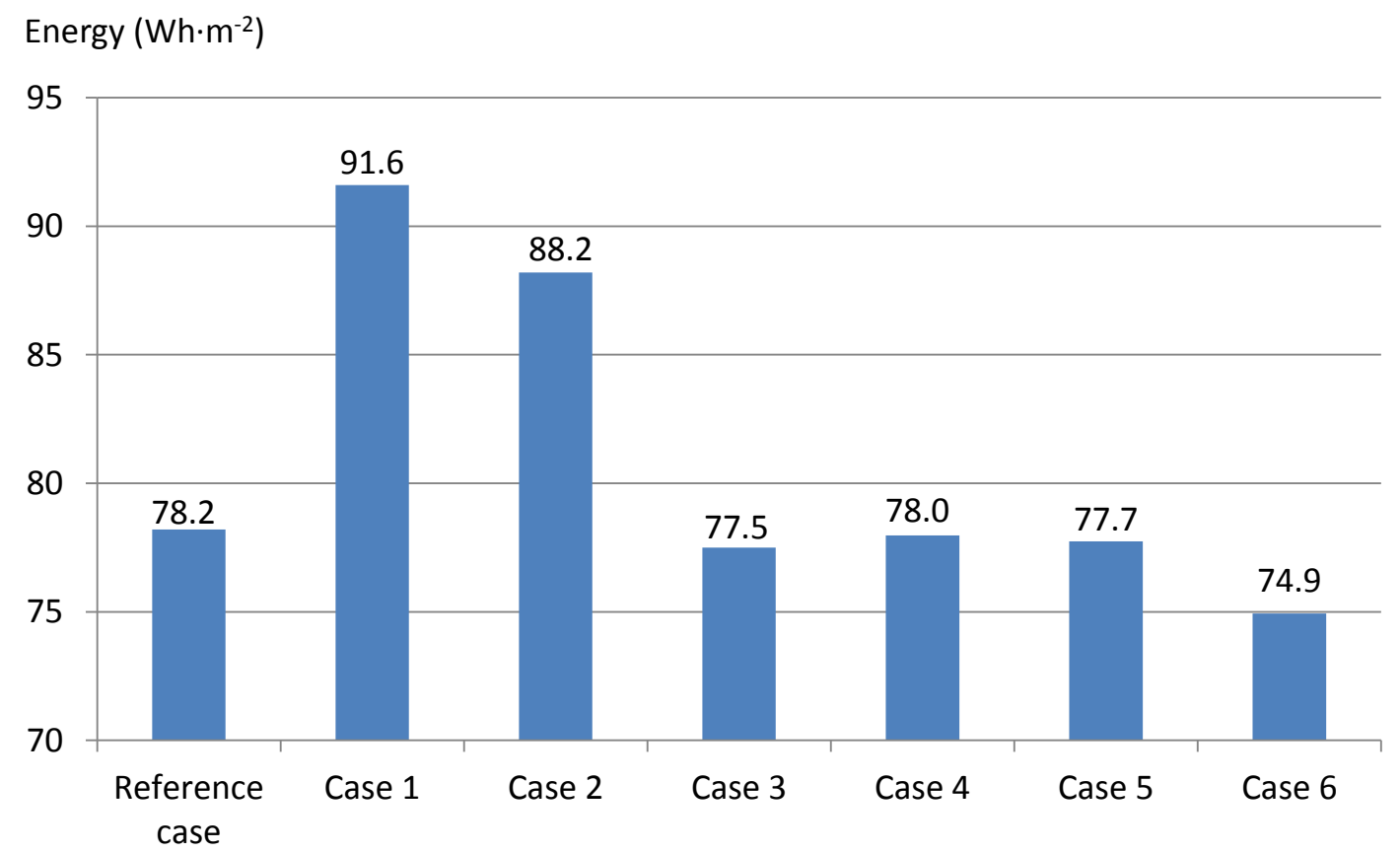

Figure 13 : Energy crossing face 2 of composite 2 (i.e. received by the isothermal compartment) for different wall configurations during the "road delivery period" of the "refrigerated vehicle" scenario.

\section{Conclusion}

This work presented a design approach for a multi-layer insulation wall containing a composite layer of PU-PCM foam with high energy storage capacity and dedicated to refrigerated vehicles. Experimental and numerical tools were developed at different scales (a few $\mathrm{mg}$ to $\approx 100 \mathrm{~g}$ ), and were used for the dynamic study of thermal transfer in several wall configurations, taking into account the thermal properties of both the composite layer and the multilayer insulating wall.

This paper first focused on the thermal characterization of the composite layer. Composite plates containing a high PCM mass rate were characterized using complementary experiments.

Thus the PCM mass rate and the latent heat of the composite layers were measured at the local and plate scales. However, we showed that it was not possible to accurately determine the thermal properties by studying the composite at the local scale (DSC: a few $\mathrm{mg}$ ). Indeed, local inhomogeneity of the PCM microbead distribution within the composite material and potential losses of PCM nodules during sampling led to erroneous evaluations of the composite latent heat with small samples: the latent heat measured with DSC was about $25 \%$ lower than the latent heat measured at 
the large scale: $65.55 \mathrm{~J} / \mathrm{g}$ and $80 \mathrm{~J} / \mathrm{g}$ for the composites 1 and 2, respectively (corresponding to a PCM mass rate of $35 \%_{\mathrm{w}}$ to $43 \%_{\mathrm{w}}$ ).

Furthermore, the measures of the thermal conductivities evolved strongly as a function of the PCM mass content. It was around two times higher compared to the reference PU foam, and increased by $11.5 \%$ when the PCM content was increased from $35 \%_{w}$ to $43 \%_{w}$.

Secondly, experiments and simulations were used to study the thermal response of different multilayer wall configurations containing a composite layer, using a refrigerated vehicle scenario. Thus paths of optimization were defined. The importance of the location of the composite layer inside the insulation wall was highlighted. For the composite plate (composite 2, i.e. containing $43 \%_{\mathrm{w}} \mathrm{PCM}$ ) studied, the composite layer should be placed close to the vehicle's outer face in order to use the cold storage capacity of the PCM material correctly. Indeed, the energy crossing the inner face of the insulation wall during the "road delivery period" decreased by $18 \%$ between the case where the composite layer was close to the inner face of the insulation wall (case 1) of the vehicle and the case where the composite layer was close to its outer face (case 3). Furthermore, the energy demand of case 3 decreased by $1.2 \%$ in comparison to the reference insulation wall of PU foam. These results showed that the wall configurations studied are not optimal, limiting the benefits of adding PCM.

Therefore, the next step is to perform an optimization study of the thickness, location and PCM mass rate of the composite layer. Among other things, this will allow quantifying the potential gains of an insulation wall containing a composite layer.

\section{Acknowledgements}

We thank Bpifrance and the Brittany Region (11007806) for funding the ISO4CAR project, labeled by the ID4CAR cluster. We also thank the company GRUAU, which was responsible for coordinating the project.

\section{References}

[1] UNEP/Earthprint. Report of the Refrigeration, Air Conditioning, and Heat Pumps Technical Options Committee. 2010.

[2] McKinnon A, Campbell J. Quick-response in the frozen food supply chain: The manufacturers' perspective. Christian Salvesen Logistics Research Paper no. 2. 1998.

[3] UNECE Transport Division. United Nations. Agreement on the international carriage of perishable foodstuffs and on the special equipment to be used for such carriage (ATP). Geneva, Switzerland: 1970.

[4] Tassou SA, De-Lille G, Ge YT. Food transport refrigeration - Approaches to reduce energy consumption and environmental impacts of road transport. Appl Therm Eng 2009;29:1467-77. doi:10.1016/j.applthermaleng.2008.06.027.

[5] Glicksman LR. "Heat transfer in Foams", Chapter 5 in: Low density cellular plastics: Physical basis of behaviour, Hilyard, C. Chunningham (Eds.). Springer Science \& Business Media; 1994.

[6] Panozzo G, Minotto G, Barizza A. Transport et distribution de produits alimentaires: situation actuelle et tendances futures. Int J Refrig 1999;22:625-639. doi:10.1016/S0140-7007(99)000237. 
[7] Glouannec P, Michel B, Delamarre G, Grohens Y. Experimental and numerical study of heat transfer across insulation wall of a refrigerated integral panel van. Appl Therm Eng 2014;73:196204. doi:10.1016/j.applthermaleng.2014.07.044.

[8] Ahmed M, Meade O, Medina MA. Reducing heat transfer across the insulated walls of refrigerated truck trailers by the application of phase change materials. Energy Convers Manag 2010;51:383-92. doi:10.1016/j.enconman.2009.09.003.

[9] Zalba B, Marín JM, Cabeza LF, Mehling H. Review on thermal energy storage with phase change: materials, heat transfer analysis and applications. Appl Therm Eng 2003;23:251-83. doi:10.1016/S1359-4311(02)00192-8.

[10] Oró E, Cabeza LF, Farid MM. Experimental and numerical analysis of a chilly bin incorporating phase change material. Appl Therm Eng 2013;58:61-7. doi:10.1016/j.applthermaleng.2013.04.014.

[11] Oró E, de Gracia A, Castell A, Farid MM, Cabeza LF. Review on phase change materials (PCMs) for cold thermal energy storage applications. Appl Energy 2012;99:513-33. doi:10.1016/j.apenergy.2012.03.058.

[12] Oró E, Miró L, Farid MM, Martin V, Cabeza LF. Energy management and CO2 mitigation using phase change materials (PCM) for thermal energy storage (TES) in cold storage and transport. Int J Refrig 2014. doi:10.1016/j.ijrefrig.2014.03.002.

[13] Tinti A, Tarzia A, Passaro A, Angiuli R. Thermographic analysis of polyurethane foams integrated with phase change materials designed for dynamic thermal insulation in refrigerated transport. Appl Therm Eng 2014. doi:10.1016/j.applthermaleng.2014.05.003.

[14] Copertaro B, Principi P, Fioretti R. Thermal performance analysis of PCM in refrigerated container envelopes in the Italian context - Numerical modeling and validation. Appl Therm Eng 2016;102:873-81. doi:10.1016/j.applthermaleng.2016.04.050.

[15] Borreguero AM, Valverde JL, Peijs T, Rodríguez JF, Carmona M. Characterization of rigid polyurethane foams containing microencapsulated Rubitherm ${ }^{\circledast}$ RT27. Part I. J Mater Sci 2010;45:4462-9. doi:10.1007/s10853-010-4529-x.

[16] You $M$, Zhang X, Wang J, Wang X. Polyurethane foam containing microencapsulated phasechange materials with styrene-divinybenzene co-polymer shells. J Mater Sci 2009;44:3141-7. doi:10.1007/s10853-009-3418-7.

[17] Aydın AA, Okutan H. Polyurethane rigid foam composites incorporated with fatty acid esterbased phase change material. Energy Convers Manag 2013;68:74-81. doi:10.1016/j.enconman.2012.12.015.

[18] Yang C, Fischer L, Maranda S, Worlitschek J. Rigid polyurethane foams incorporated with phase change materials: A state-of-the-art review and future research pathways. Energy Build 2015;87:25-36. doi:10.1016/j.enbuild.2014.10.075.

[19] INERTEK | Winco Technologies n.d. http://www.winco-tech.com/fr/produit/inertek/ (accessed August 31, 2016).

[20] Kuznik F, David D, Johannes K, Roux J-J. A review on phase change materials integrated in building walls. Renew Sustain Energy Rev 2011;15:379-91. doi:10.1016/j.rser.2010.08.019.

[21] Dumas J-P, Gibout S, Zalewski L, Johannes K, Franquet E, Lassue S, et al. Interpretation of calorimetry experiments to characterise phase change materials. Int J Therm Sci 2014;78:48-55. doi:10.1016/j.jithermalsci.2013.11.014.

[22] Mehling H, Cabeza LF. Heat and cold storage with PCM: An up to date introduction into basics and applications. Springer; 2008.

[23] Bony J, Citherlet S. Numerical model and experimental validation of heat storage with phase change materials. Energy Build 2007;39:1065-72. doi:10.1016/j.enbuild.2006.10.017.

[24] Joulin A, Zalewski L, Lassue S, Naji H. Experimental investigation of thermal characteristics of a mortar with or without a micro-encapsulated phase change material. Appl Therm Eng 2014;66:171-80. doi:10.1016/j.applthermaleng.2014.01.027. 
[25] Franquet E, Gibout S, Tittelein P, Zalewski L, Dumas J-P. Experimental and theoretical analysis of a cement mortar containing microencapsulated PCM. Appl Therm Eng 2014;73:32-40. doi:10.1016/j.applthermaleng.2014.06.053. 